\title{
Volatile Organic Compound Removal Efficiency of Green and Variegated Foliage Plants Grown under Different Light Intensities
}

\author{
Kwang Jin Kim ${ }^{1}$, Mohammad Khalekuzzaman ${ }^{2}$ *, Charlotte Concepcion Shagol ${ }^{1}$, Jung Nam Suh ${ }^{1}$, and Hyeon Ju Kim ${ }^{1}$ \\ ${ }^{1}$ Urban Agriculture Research Division, National Institute of Horticultural and Herbal Science, Rural Development Administration, Wanju \\ 55365, South Korea \\ ${ }^{2}$ Department of Genetic Engineering and Biotechnology, University of Rajshahi, Rajshahi- 6205, Bangladesh
}

\begin{abstract}
This study investigated the effect of leaf form or phenotype and light intensity on the toluene, xylene, and ethylbenzene removal of three foliage plants. Green and variegated forms of Ardisia pusilla, Scindapsus aureus, and Hedera helix plants were grown under 10 and $20 \mathrm{umol} \cdot \mathrm{m}^{-2} \cdot \mathrm{s}^{-1}$ light intensities for 8 months and were tested for their volatile organic compound (VOC) removal efficiency for $15 \mathrm{~h}$. In general, variegated forms of the plant species have higher VOC removal after $15 \mathrm{~h}$ of VOC exposure than green plants, particularly when grown in $10 \mathrm{\mu mol} \cdot \mathrm{m}^{-2} \cdot \mathrm{s}^{-1}$. This is more evident in $A$. pusilla and $S$. aureus than in $H$. helix. The highest rate of toluene, $m^{-}, p^{-}$, and $\sigma^{-x y l e n e}$ removal per hour by plants grown under $10 \mathrm{umol} \cdot \mathrm{m}^{-2} \cdot \mathrm{s}^{-1}$ was achieved by variegated $A$. pusilla, while for ethylbenzene, variegated $A$. pusilla and variegated $H$. helix had the highest removal rate per hour. In plants grown in $20 \mu \mathrm{mol} \cdot \mathrm{m}^{-2}$. $s^{-1}$ light intensity, variegated and green $H$. helix have the highest removal rate per hour of toluene and $m-, p$-, and $\sigma$-xylene. For ethylbenzene, variegated $A$. pusilla and green and variegated $H$. helix had the highest removal rates per hour. The plant with the lowest removal rate per hour for all five VOCs was green $S$. aureus grown under both light intensities. The percentage VOC removal rate of variegated over green plants was $22 \%$ higher at a lower light intensity.
\end{abstract}

Keywords: air pollutants, air purification, indoor air quality, indoor plants

\section{Introduction}

With people, particularly in urban areas, generally spending 80-90\% of their time in indoors (Wang et al., 2007), indoor air quality has become a significant issue in recent years. With new innovations in construction technology, modern airtight buildings are equipped with air-conditioning systems and synthetic materials for decorating and remodeling purposes. As a result, the concentration of indoor air pollutants may increase to several hundred times the level outdoors (Brown, 1997; Fisk, 2000; Orwell et al., 2004). Volatile organic compounds (VOCs) such as formaldehyde, toluene and xylene are highly toxic and may trigger immediate or long-term harm to human health (Wolkoff, 2003). Health-related problems associated with staying indoors such as sick building syndrome, building-related illness or multiple chemical sensitivity have been reported frequently in recent years (Runeson et al., 2006; Orwell et al., 2006; Liu, 2007; Tsai et al., 2012).

This research was conducted with the support of the Rural Development Administration for the project PJ01221501201.

Received: September 14, 2017, Revised: September 21, 2017, Accepted: October 18, 2017

*Comesponding author: kwangjin@korea.kr 
Many foliage plants are often used as indoor house plants due to their attractive foliage and ability to grow in limited light (Chen and Henny, 2008; Kim et al., 2012). Variegation is an important trait of some foliage plants such as Hedera helix, Ardisia pusilla and Scindapsus aureus, which may influence the preference of consumers. Variegation in plants is a phenomenon that has benefitted horticulture both economically and scientifically. Variegation can be defined as the presence of distinct patterns of varying colors on an organ, which may be patterned or nonpatterned (Marcotrigiano, 1997). Aside from the aesthetic value it provides, variegated forms of plants have been used to study $\mathrm{CO}_{2}$ assimilation, photosynthesis, etc. Variegation may occur due to reduced chlorophyll or may be produced by structural color. It has also been associated with reduced herbivore damage (Campitelli et al., 2008). Aside from these benefits, the advantages of foliar variegation have not yet been fully understood or utilized.

Light is an important environmental factor that influences plant growth and development. Reduced light intensity is the most limiting factor for indoor plant growth (Manaker, 1997). Outdoor light intensity is generally higher than 1,000 $\mu \mathrm{mol} \cdot \mathrm{m}^{-2} \cdot \mathrm{s}^{-1}$ on sunny days, while typical indoor light intensity is less than $40 \mu \mathrm{mol} \cdot \mathrm{m}^{-2} \cdot \mathrm{s}^{-1}$ (Manaker, 1997). Plants require a particular light environment for proper growth and development (Maloof et al., 2001). Moreover, to sustain higher photosynthetic capacity or survival, plants modify their morphology, physiology, and biomass allocation under different light conditions (Sims and Pearoy, 1992; Feng et al., 2004). Different plant species respond differently to light intensity.

It is well established that foliage plants in association with rhizosphere microorganisms can effectively improve indoor air quality by reducing many different pollutants, including volatile organic compounds such as formaldehyde (Kim et al., 2008; 2010; Aydogan and Montoya, 2011), benzene (Orwell et al., 2004; Irga et al., 2013; Torpy et al., 2013), toluene (Oyabu et al., 2005a; Orwell et al., 2006; Kim et al., 2012), and xylene (Wolverton and Wolverton, 1993; Kim et al., 2014), thus reducing the risk of sick building syndrome (Kim et al., 2011). However, VOC removal efficiency varies substantially among plant species (Yoo et al., 2006; Kim et al., 2014), with many factors affecting it.

The aim of the present study was to investigate the toluene, xylene, and ethylbenzene removal efficiency of three foliage plant species (Ardisia pusilla, Scindapsus aureus, and Hedera helix) as affected by plant form (green and variegated forms) and light intensity treatments.

\section{Materials and Methods}

\section{Plant materials}

Two-year-old Ardisia pusilla, Scindapsus aureus, and Hedera helix plants were obtained from a commercial nursery at

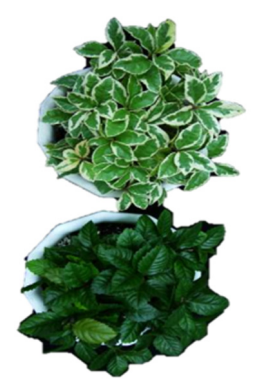

A

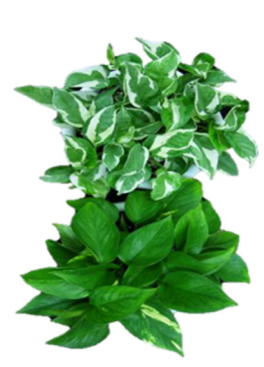

$\mathrm{B}$

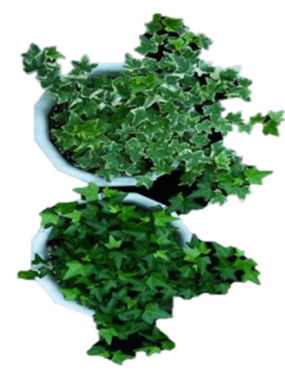

$\mathrm{C}$

Figure 1. Indoor foliage plants used in the study. Variegated (top row) and green plants (bottom row) of Ardisia pusilla (A), Scindapsus aureus (B), and Hedera helix (C). 
Table 1. Leaf area of the different plant species used in the experiment.

\begin{tabular}{cccc}
\hline \multirow{2}{*}{$\begin{array}{c}\text { Light intensity } \\
\left(\mu \mathrm{mol} \cdot \mathrm{m}^{-2} \cdot \mathrm{s}^{-1}\right)\end{array}$} & Plant species & Green form & Leaf area $\left(\mathrm{m}^{2}\right)$ \\
\cline { 3 - 4 } & & $0.12 \pm 0.022^{*}$ & Variegated form \\
\hline 10 & Ardisia pusilla & $0.24 \pm 0.035$ & $0.08 \pm 0.023$ \\
& Scindapsus aureus & $0.14 \pm 0.016$ & $0.14 \pm 0.015$ \\
& Hedera helix & $0.14 \pm 0.002$ & $0.09 \pm 0.013$ \\
\hline 20 & Ardisia pusilla & $0.23 \pm 0.015$ & $0.12 \pm 0.003$ \\
& Scindapsus aureus & $0.12 \pm 0.009$ & $0.16 \pm 0.028$ \\
& Hedera helix & & $0.08 \pm 0.012$ \\
\hline
\end{tabular}

* Values are the means of 3 replicates \pm SE.

Suwon, South Korea. Green and variegated plant forms for each species were used in the study (Fig. 1). The leaf area of the test plants is shown in Table 1. The plants were transplanted in $19-\mathrm{cm}$ diameter and $2.2 \mathrm{~L}$ volume plastic pots containing a uniform growing medium comprised of Mix\#4 (Sun Grow Horticulture, Bellevue, WA), bark-humus (Biocom Co., Seoul, Korea), and sand at a ratio of 5:1:1, v/v/v. Mix \#4 contained Canadian sphagnum peat-moss ( $55 \%$ to $65 \%$ by volume), perlite, dolomitic lime, gypsum, and a wetting agent. The potted plants were grown in a shaded greenhouse for two weeks after transplanting. The temperature in the shaded greenhouse ranged from $24-26^{\circ} \mathrm{C}$. The plants were watered every 3 days, with the excess water allowed to drain. All plants were watered two days before the gas treatments. All plants were then acclimated in an indoor environment as per Kim et al. (2010) with a light intensity of $20 \mu \mathrm{mol} \cdot \mathrm{m}^{-2} \cdot \mathrm{s}^{-1}$ for two weeks at room temperature $\left(23 \pm 2^{\circ} \mathrm{C}\right)$.

\section{Light treatment}

After acclimation, the plants were grown in separate chambers with 10 and $20 \mu \mathrm{mol} \cdot \mathrm{m}^{-2} \cdot \mathrm{s}^{-1}$ light intensities for eight months using fluorescent lights. The chambers were maintained at $24 \pm 1{ }^{\circ} \mathrm{C}$ with a $12 / 12$-h day/night photoperiod.

\section{VOC treatment system and chamber conditions}

The treatment system consisted of controlled-environment rooms, test chambers and a gas generator. The test chambers were made of inert materials (i.e. glass surfaces, stainless steel frame, and Teflon) that were impervious to VOCs. The chamber doors were sealed using an adhesive closed-pore neoprene foam tape and adjustable metal clips (Kim et al., 2011). The volume of each chamber was $1.0 \mathrm{~m}^{3}(90 \times 90 \times 123 \mathrm{~cm})$. Using a sealed external pump, the interior air was circulated $\left(6 \mathrm{~L} \cdot \mathrm{min}^{-1}\right)$ and released at the bottom of the chamber through a stainless steel tube $(0.64)$ with holes, and tested for toluene and xylene concentrations.

Three potted plants were placed in a chamber with a light intensity of $20 \pm 1 \mu \mathrm{mol} \cdot \mathrm{m}^{-2} \cdot \mathrm{s}^{-1}$ using fluorescent lights for 15 hours. Each treatment combination was tested in three replicates. Chambers without plants were used to determine VOC losses that were not due to the plants (e.g. leakage, adsorption, chemical reactions).

\section{Gas exposure and measurement}

The plants were pretreated with liquid toluene (Sigma-Aldrich Co., Inc., USA) and xylene (Duksan Pure Chemical Co., Ltd., Ansan, Korea), since pretreatment is known to enhance the phytoremediation potential of plants for VOCs. Using a 
generator, liquid toluene or xylene along with air and only air was allowed to pass through a connecting tube and transformed into a gaseous state. Gaseous toluene and xylene were introduced into a test chamber containing three plants as previously described (Kim et al., 2008; 2011), and allowed to equilibrate for $15 \mathrm{~min}$. The internal concentration was about $0.5 \mu \mathrm{L} \cdot \mathrm{L}^{-1}$ for the stimulation treatment. The plants remained in the stimulation treatment for 15 hours and then were moved to fresh air for 2 hours. After the stimulation treatment, the subsequent toluene, xylene and ethylbenzene removal by the plants was determined. The plants were exposed to a gas mix of $0.5 \mu \mathrm{L} \cdot \mathrm{L}^{-1}$ of toluene and $0.5 \mu \mathrm{L} \cdot \mathrm{L}^{-1}$ xylene in a chamber. Ethylbenzene was formed from toluene so no additional ethylbenzene was used in the study. VOC removal was measured within the chamber at intervals of $3 \mathrm{~h}$ for $15 \mathrm{~h}$. Changes in VOC within the chamber were expressed in the form of concentration $\left(\mu \mathrm{g} \cdot \mathrm{m}^{-3}\right)$ and removal efficiency on a leaf area $(\mathrm{LA})$ basis $\left(\mu \mathrm{g} \cdot \mathrm{m}^{-3} \cdot \mathrm{m}^{-2}\right.$ leaf area).

\section{VOC quantification}

Air samples were collected at the appropriate time intervals with a quartz cold trap [120 mm long, $2.9 \mathrm{~mm}$ o.d., $1.0 \mathrm{~mm}$ i.d. (inlet), $2.0 \mathrm{~mm}$ i.d. (outlet); Markes International Ltd., Llantrisant, U.K.] connected to each chamber and the air was collected for $5 \mathrm{~min}$ at $5 \mathrm{~mL} \cdot \mathrm{min}^{-1}$. An automated thermal desorption system with Air Server autosampler (UNITY; Markes International Ltd.) was connected to the injection port of the gas chromatography-mass spectroscopy machine (TRACE DSQ; Thermo Electron Co., Waltham, MA) (Kim et al., 2011). The desorbed sample was cryofocused at $5^{\circ} \mathrm{C}$ for 5 min on the first few centimeters of the column, desorbed at $280^{\circ} \mathrm{C}$, and separated using a ZB-624 capillary column (30 $\mathrm{m}$ length $\times$ $0.25 \mathrm{~mm}$ i.d., $1.40 \mu \mathrm{m}$ film thickness of $6 \%$ cyanopropylphenyl, $94 \%$ dimethylpolysiloxane; Phenomenex, Torrance, CA). The injection port temperature was $180^{\circ} \mathrm{C}$ with a split ratio of $29: 1$. Helium was used as the carrier gas at a flow rate of 1.0 $\mathrm{mL} \cdot \mathrm{min}^{-1}$. The column temperature was held at $45^{\circ} \mathrm{C}$ for $1 \mathrm{~min}$, increased to $100^{\circ} \mathrm{C}$ at a rate of $15^{\circ} \mathrm{C} \cdot \mathrm{min}^{-1}$, and held for 1 min and then increased to $135^{\circ} \mathrm{C}$ at a rate of $5^{\circ} \mathrm{C} \cdot \mathrm{min}^{-1}$.

\section{Data analysis}

Gas concentrations were expressed as $\mu \mathrm{g} \cdot \mathrm{m}^{-3}$ with the data normalized to $24 \pm 1{ }^{\circ} \mathrm{C}$ and $100 \mathrm{kPa}$ (Hines et al., 1993). Data were expressed as the average of three replicates. The concentration of toluene or xylene [Eq. 1] and the removal efficiency per unit leaf area and time [Eq. 2] were calculated (Kim et al., 2008; 2011) as:

$$
\begin{aligned}
& \text { VOC concentration }\left(\mu \mathrm{g} \cdot \mathrm{m}^{-3}\right)=[(\mathrm{Pi}-(\mathrm{Ci}-\mathrm{C}))-\mathrm{P}] \times(\mathrm{F} \times \mathrm{CV}) \\
& \operatorname{VOC} \text { removal }\left(\mu \mathrm{g} \cdot \mathrm{m}^{-3} \cdot \mathrm{m}^{-2} \text { leaf area }\right)=[(\mathrm{Pi}-(\mathrm{Ci}-\mathrm{C}))-\mathrm{P}] \times(\mathrm{F} \times \mathrm{CV}) / \mathrm{L}
\end{aligned}
$$

where $\mathrm{P}$ is the gas concentration measured in a chamber with plants $\left(\mu \mathrm{L} \cdot \mathrm{L}^{-1}\right)$; $\mathrm{Pi}$ is the initial gas concentration measured in a chamber with plants $\left(\mu \mathrm{L} \cdot \mathrm{L}^{-1}\right) ; \mathrm{C}$ is the gas concentration measured in a chamber without plants $\left(\mu \mathrm{L} \cdot \mathrm{L}^{-1}\right)$; $\mathrm{Ci}$ is the initial gas concentration measured in a chamber without plants $\left(\mu \mathrm{L} \cdot \mathrm{L}^{-1}\right) ; \mathrm{F}$ is the toluene or xylene conversion factor for volume $\left(\mu \mathrm{L} \cdot \mathrm{L}^{-1}\right)$ to mass $\left(\mu \mathrm{L} \cdot \mathrm{L}^{-1}\right) ; \mathrm{CV}$ is the volume of the chamber $\left(\mathrm{m}^{3}\right)$; and $\mathrm{L}$ is the total leaf area per chamber $\left(\mathrm{m}^{2}\right)$. The loss of toluene, xylene, or ethylbenzene $(\mathrm{Ci}-\mathrm{C})$ not due to the plant or media was determined using empty chambers.

\section{Results and Discussions}

There were differences in VOC removal between green and variegated forms of the different indoor plants grown under two 
light intensities. Variegated forms of the three plant species in $10 \mu \mathrm{mol} \cdot \mathrm{m}^{-2} \cdot \mathrm{s}^{-1}$ have higher toluene removal than their green counterparts after $15 \mathrm{~h}$ of exposure. The highest toluene removal in plants grown under $10 \mu \mathrm{mol} \cdot \mathrm{m}^{-2} \cdot \mathrm{s}^{-1}$ was by variegated A. pusilla, followed closely by variegated H. helix (Fig. 2). Among the indoor plants, green S. aureus had the lowest removal of toluene. The highest removal of toluene at higher light intensity $\left(20 \mu \mathrm{mol} \cdot \mathrm{m}^{-2} \cdot \mathrm{s}^{-1}\right)$ was by green and variegated $H$. helix, followed by green and variegated A. pusilla. In plants grown under $20 \mu \mathrm{mol} \cdot \mathrm{m}^{-2} \cdot \mathrm{s}^{-1}$, a significant difference in toluene removal between green and variegated plants was only observed in $S$. aureus. Apparently, the difference in leaf phenotype or form, i.e. green and variegated, did not affect toluene removal of A. pusilla and H. helix in this light intensity.

An almost similar trend was observed in the $m$-, $p$-xylene (Fig. 3) and $o$-xylene (Fig. 4) removal by the green and variegated forms of the three indoor plants. In lower light intensity of $10 \mu \mathrm{mol} \cdot \mathrm{m}^{-2} \cdot \mathrm{s}^{-1}$, generally the variegated plants, with the exception of $H$. helix, showed higher removal efficiency over the course of $15 \mathrm{~h}$. For $m-, p$-, $o$-xylene, variegated A. pusilla showed the highest removal, whereas green $S$. aureus had the lowest removal (Figs. 3 and 4). There was no significant difference in the $m$ - and $p$-xylene removal by green and variegated $H$. helix grown either in 10 or in $20 \mu \mathrm{mol} \cdot \mathrm{m}^{-2} \cdot \mathrm{s}^{-1}$ light intensity. However, $o$-xylene variegated $H$. helix showed higher removal in lower light intensity starting at $9 \mathrm{~h}$ after exposure (Fig. 4).

Of the plants grown in $10 \mu \mathrm{mol} \cdot \mathrm{m}^{-2} \cdot \mathrm{s}^{-1}$, ethylbenzene removal was highest in variegated $A$. pusilla and variegated $H$. helix (Fig. 5). The green plants had a removal effect about 50-64\% lower than the variegated forms. However, in plants grown under $20 \mu \mathrm{mol} \cdot \mathrm{m}^{-2} \cdot \mathrm{s}^{-1}$, the difference in removal between the two forms was not so pronounced in the two plant species. S. aureus under 10 and $20 \mu \mathrm{mol} \cdot \mathrm{m}^{-2} \cdot \mathrm{s}^{-1}$ showed much lower ethylbenzene removal among the plant species; however, the variegated form showed higher removal, particularly under $20 \mu \mathrm{mol} \cdot \mathrm{m}^{-2} \cdot \mathrm{s}^{-1}$.

Furthermore, variegated plants showed higher VOC removal efficiency per hour. Variegated A. pusilla grown under 10 $\mu \mathrm{mol} \cdot \mathrm{m}^{-2} \cdot \mathrm{s}^{-1}$ had the highest removal per hour, while green $S$. aureus had the lowest toluene removal rate per hour (Fig. 6).

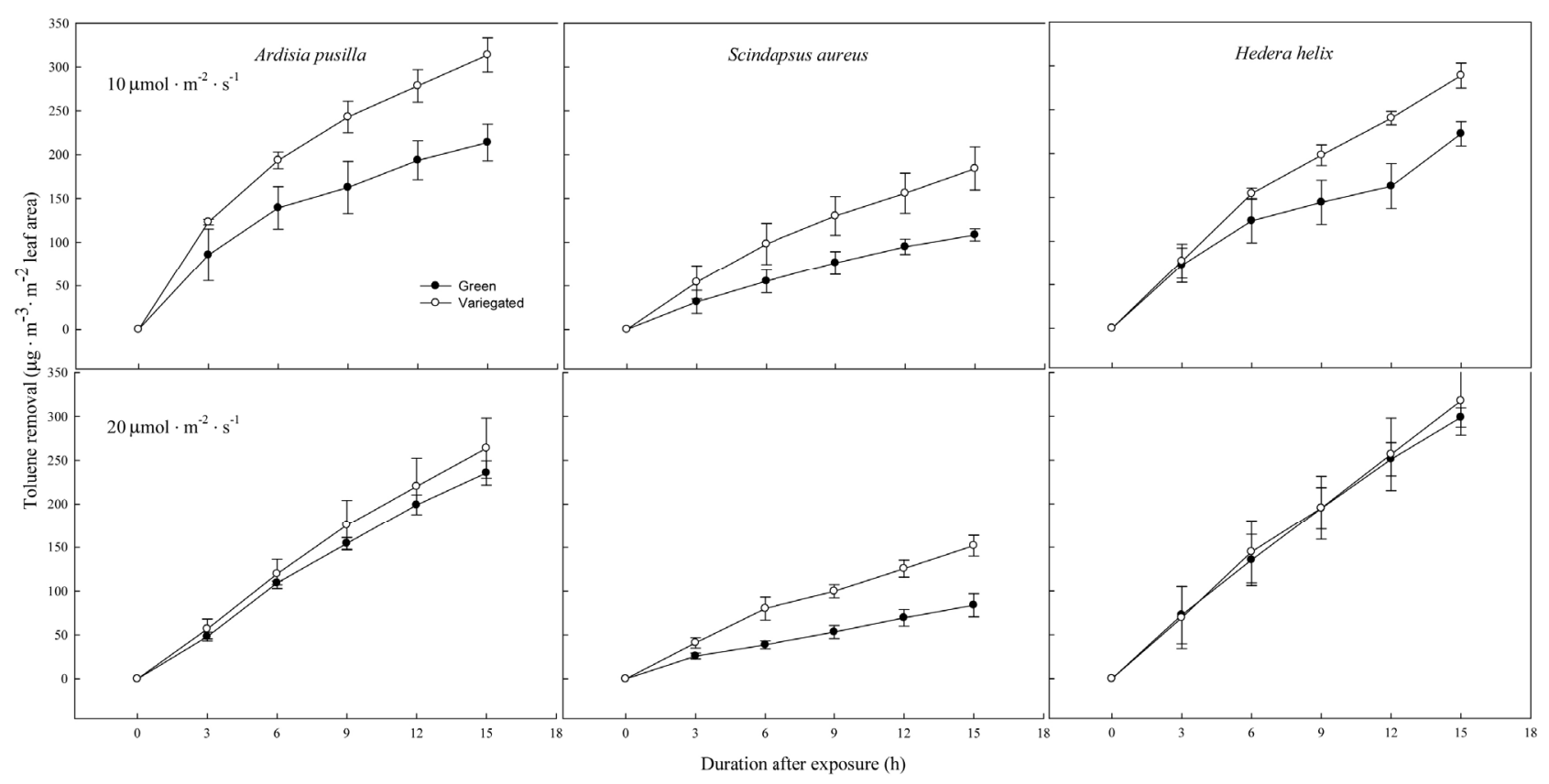

Figure 2. Toluene removal by green and variegated forms of $A$. pusilla, S. aureus, and $H$. helix grown under $10 \mu \mathrm{mol} \cdot \mathrm{m}^{-2} \cdot \mathrm{s}^{-1}$ (top row) and $20 \mathrm{\mu mol} \cdot \mathrm{m}^{-2} \cdot \mathrm{s}^{-1}$ (bottom row) light intensities. Initial concentration of toluene was $0.5 \mu \mathrm{L} \cdot \mathrm{L}^{-1}$. Each value is a mean of 3 replicates. Error bars are \pm SE. 
Among the plants grown in $20 \mu \mathrm{mol} \cdot \mathrm{m}^{-2} \cdot \mathrm{s}^{-1}$, variegated and green $H$. helix have the highest removal rate of toluene. It is also notable that variegated plants, particularly of $A$. pusilla, have a higher removal rate of toluene per hour when grown under $10 \mu \mathrm{mol} \cdot \mathrm{m}^{-2} \cdot \mathrm{s}^{-1}$ than when grown under $20 \mu \mathrm{mol} \cdot \mathrm{m}^{-2} \cdot \mathrm{s}^{-1}$. Similarly, S. aureus has higher toluene removal rate under lower light intensity, with variegated forms having higher removal rate per hour.

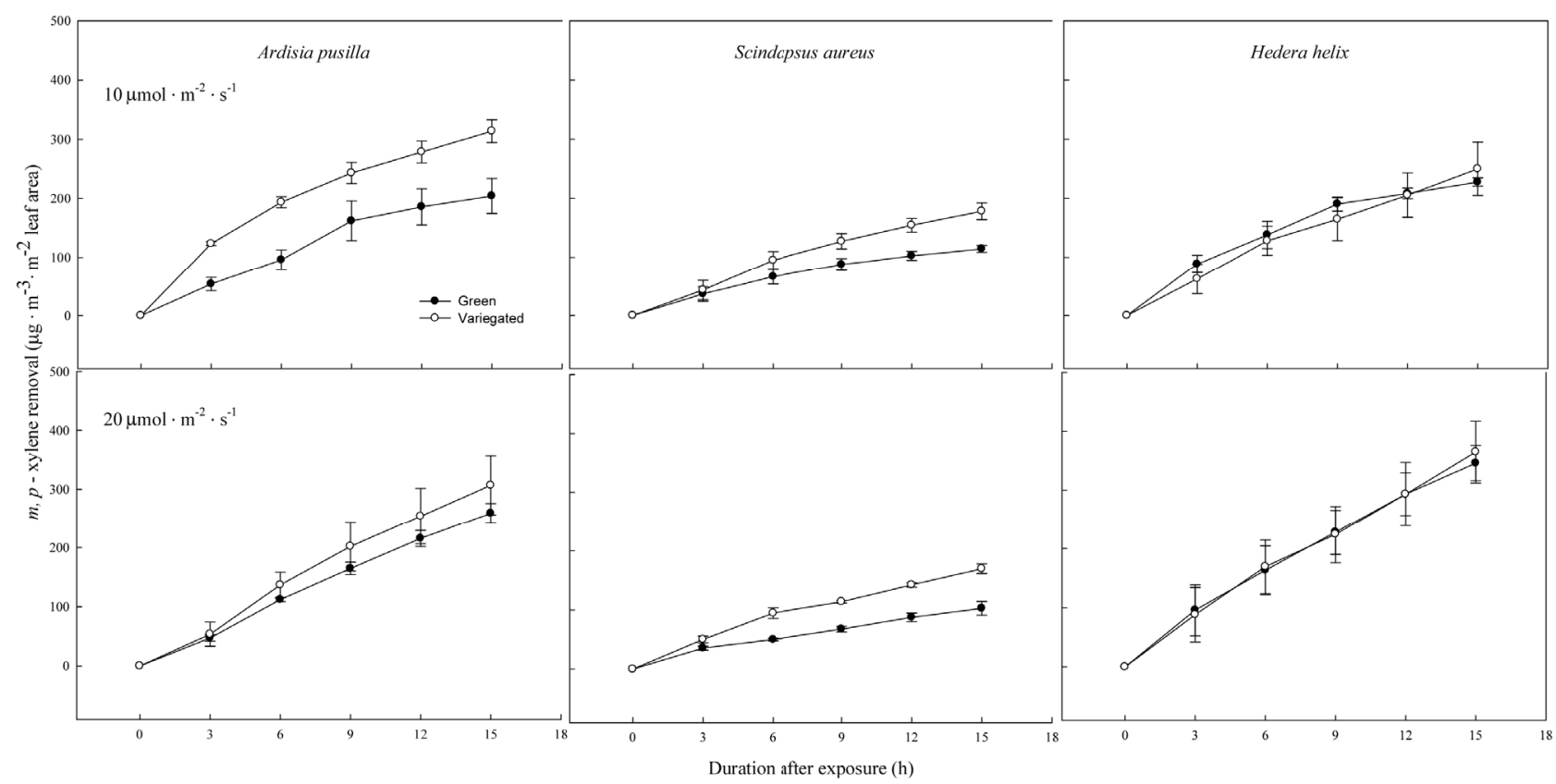

Figure 3. $m$ - and $p$-xylene removal of green and variegated plants of $A$. pusilla, $S$. aureus, and $H$. helix grown under 10 $\mathrm{umol} \cdot \mathrm{m}^{-2} \cdot \mathrm{s}^{-1}$ (top row) and $20 \mathrm{\mu mol} \cdot \mathrm{m}^{-2} \cdot \mathrm{s}^{-1}$ (bottom row) light intensities. Initial concentration of xylene was 0.5 $\mu \mathrm{L} \cdot \mathrm{L}^{-1}$. Each value is a mean of 3 replicates. Error bars are $\pm \mathrm{SE}$.

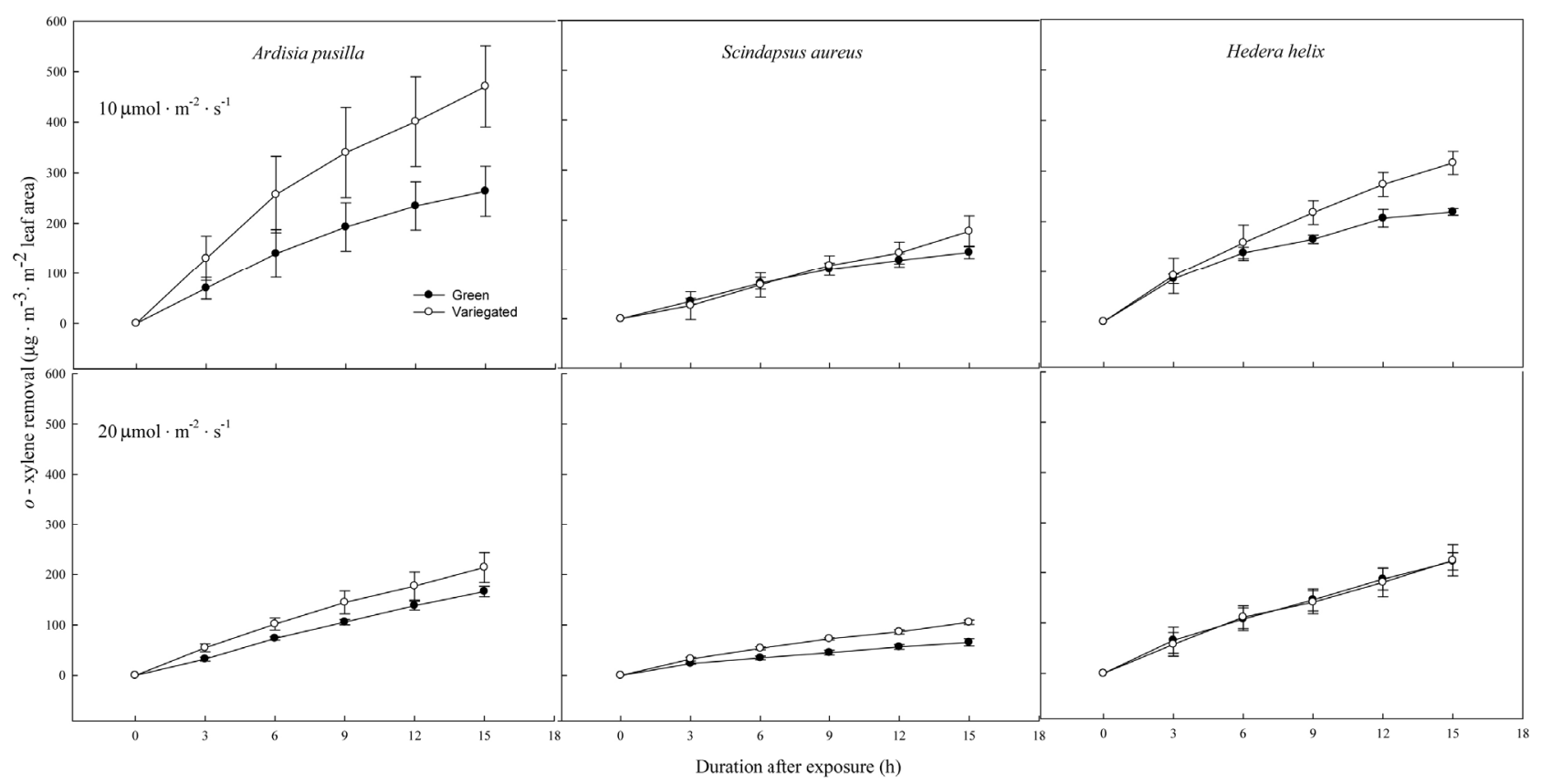

Figure 4. $\sigma$ xylene removal of green and variegated plants of $A$. pusilla, S. aureus, and $H$. helix grown under $10 \mu \mathrm{mol} \cdot \mathrm{m}^{-2} \cdot \mathrm{s}^{-1}$ (top row) and $20 \mu \mathrm{mol} \cdot \mathrm{m}^{-2} \cdot \mathrm{s}^{-1}$ (bottom row) light intensities. Initial concentration of xylene was $0.5 \mu \mathrm{L} \cdot \mathrm{L}^{-1}$. Each value is a mean of 3 replicates. Error bars are \pm SE. 
$m$ - and $p$-xylene removal rates per hour were highest in green and variegated $H$. helix grown under $20 \mu \mathrm{mol} \cdot \mathrm{m}^{-2} \cdot \mathrm{s}^{-1}$ (Figs. 6 and 7). Removal rates per hour of S. aureus were similar regardless of plant form and light intensity. On the other hand, H. helix, both green and variegated, showed higher $m$ - and $p$-xylene removal rates per hour when grown in higher

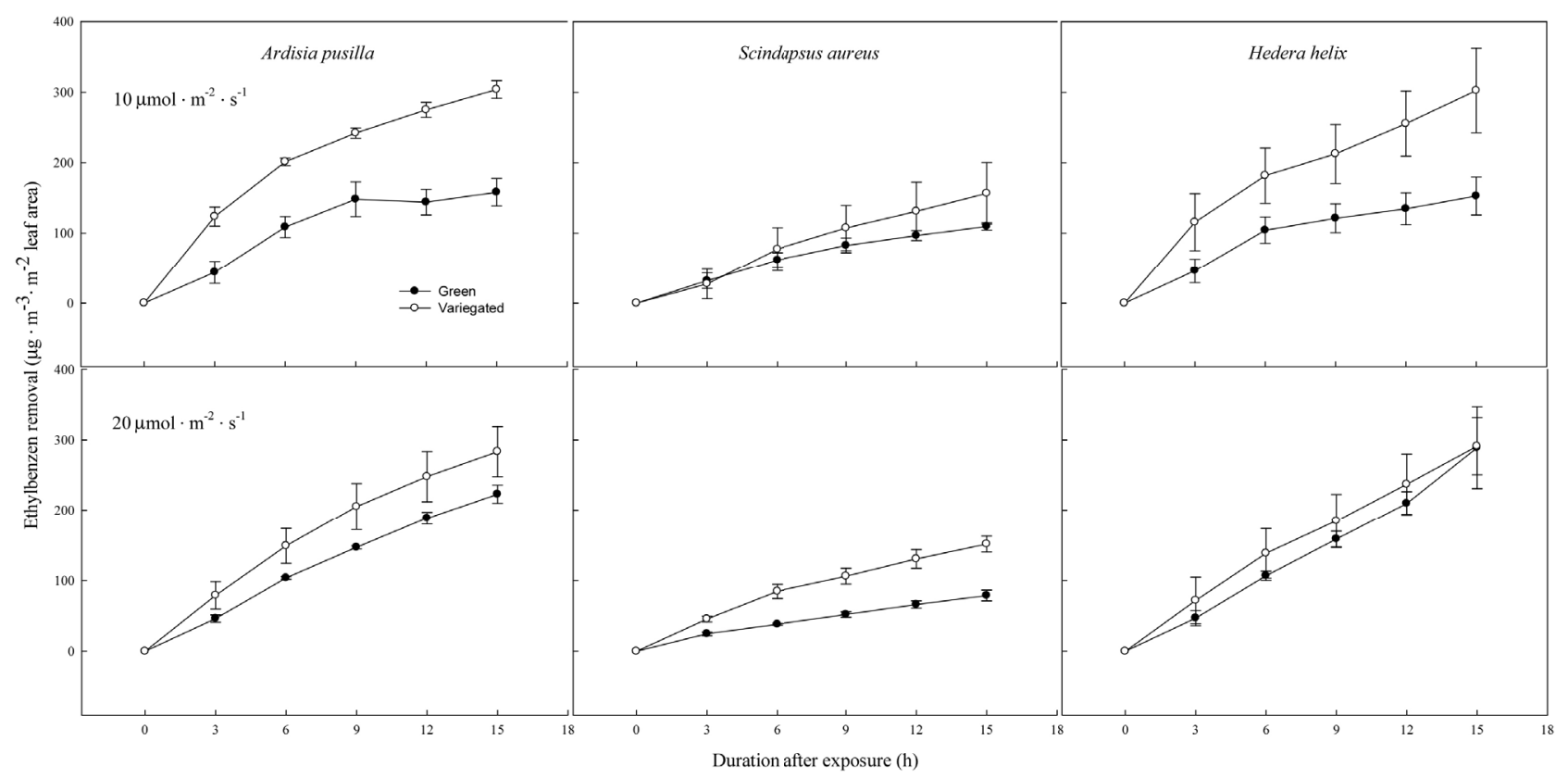

Figure 5. Ethylbenzene removal of green and variegated plants of $A$. pusilla, S. aureus, and $H$. helix grown under $10 \mu$ $\mathrm{mol} \cdot \mathrm{m}^{-2} \cdot \mathrm{s}^{-1}$ (top row) and $20 \mathrm{\mu mol} \cdot \mathrm{m}^{-2} \cdot \mathrm{s}^{-1}$ (bottom row) light intensities. Initial concentration of xylene was 0.5 $\mu \mathrm{L} \cdot \mathrm{L}^{-1}$. Each value is a mean of 3 replicates. Error bars are $\pm \mathrm{SE}$.

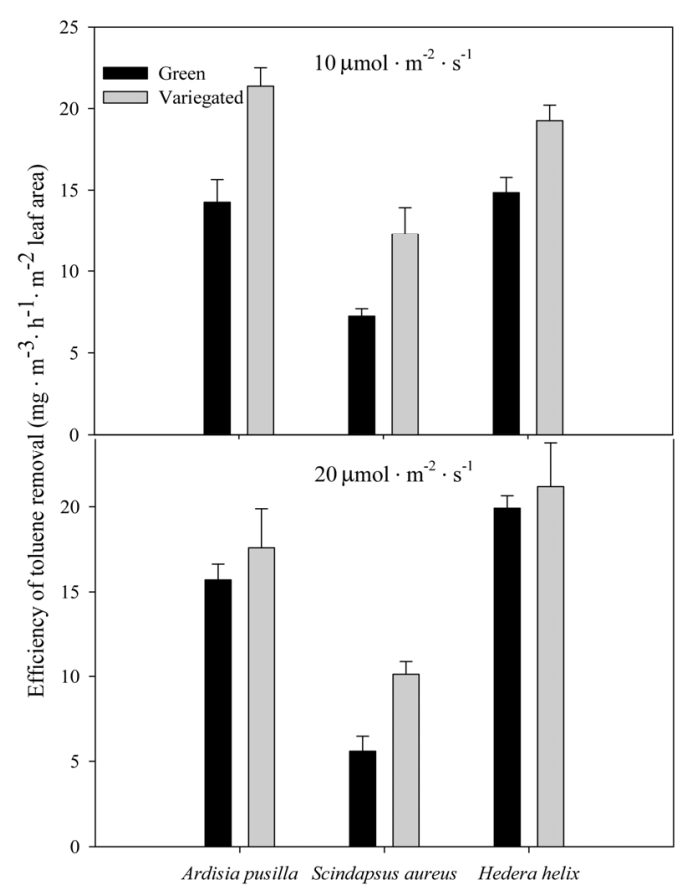

Figure 6. Removal rate of toluene per hour by green and variegated plants of $A$. pusilla, S. aureus, and $H$. helix grown under 10 (top) and $20 \mu \mathrm{mol} \cdot \mathrm{m}^{-2} \cdot \mathrm{s}^{-1}$ (bottom) light intensities. Each value is a mean of 3 replicates. Error bars are \pm SE.

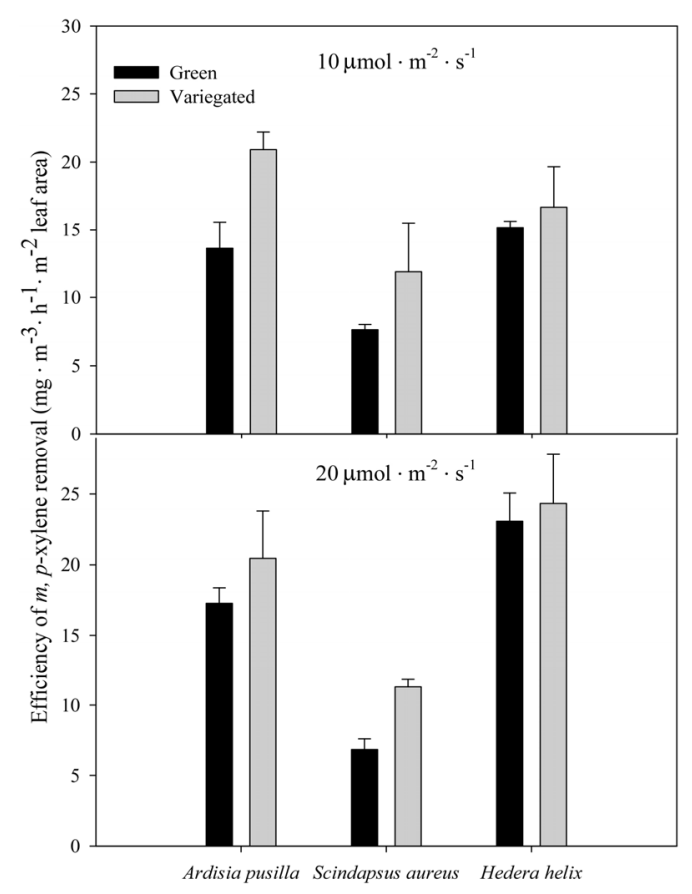

Figure 7. Removal rate of $m$ - and $p$-xylene per hour by green and variegated plants of $A$. pusilla, $S$. aureus, and H. helix grown under 10 (top) and $20 \mu \mathrm{mol} \cdot \mathrm{m}^{-2} \cdot \mathrm{s}^{-1}$ (bottom) light intensities. Each value is a mean of 3 replicates. Error bars are \pm SE. 
light intensity. $o$-xylene removal rates were higher in plants grown under lower light intensity. Variegated forms of each plant species grown under lower light intensity showed higher removal rates per hour (Fig. 8). Removal rates of ethylbenzene per hour of variegated plants were similar regardless of light intensity condition (Fig. 9). On the other hand, the green plants of the three plant species showed increased removal rates per hour when grown under the higher light intensity.

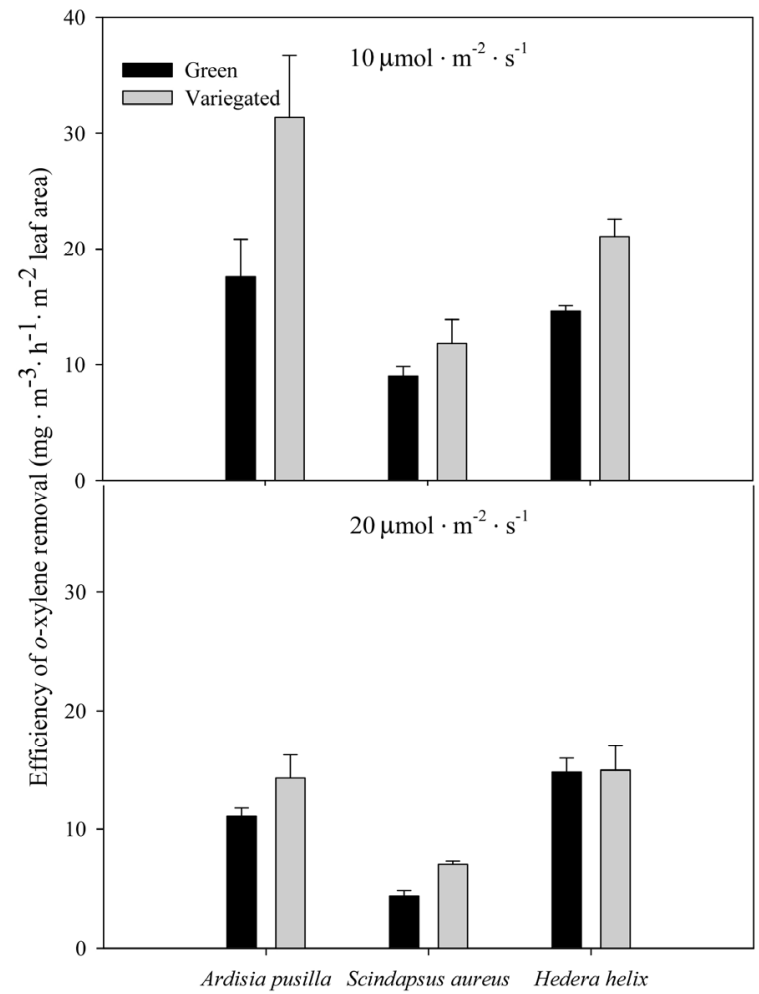

Figure 8. Removal rate of $\sigma$-xylene per hour by green and variegated plants of $A$. pusilla, $S$. aureus, and $H$. helix grown under 10 (top) and $20 \mu \mathrm{mol} \cdot \mathrm{m}^{-2} \cdot \mathrm{s}^{-1}$ (bottom) light intensities. Each value is a mean of 3 replicates. Error bars are \pm SE.

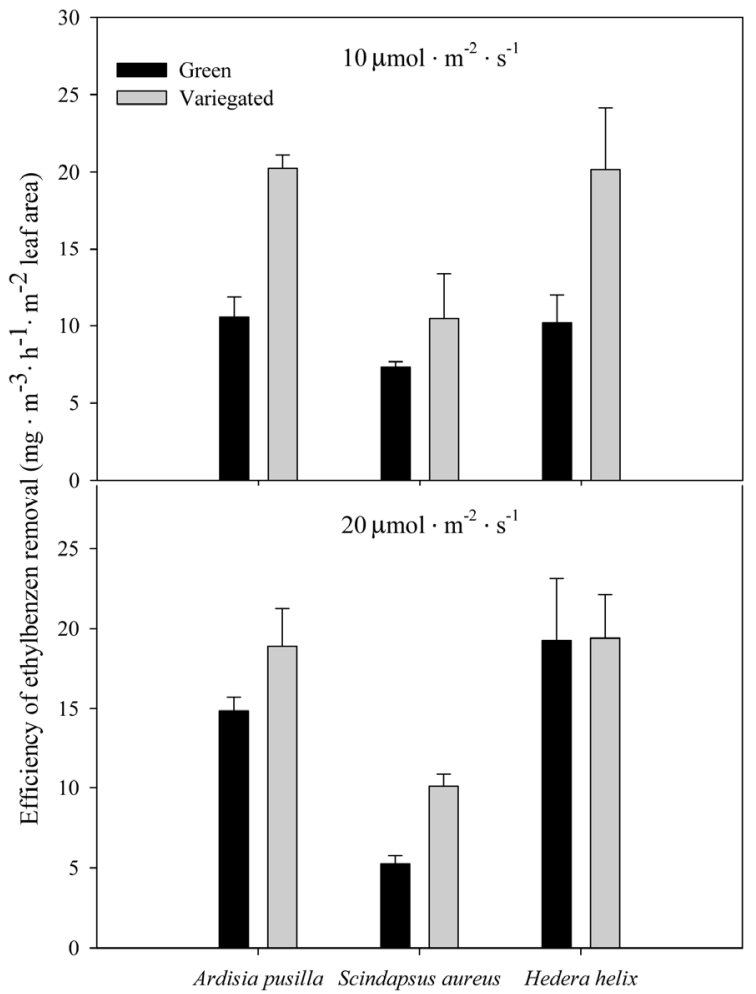

Figure 9. Removal rate of ethylbenzene per hour by green and variegated plants of $A$. pusilla, S. aureus, and H. helix grown under 10 (top) and $20 \mathrm{\mu mol} \cdot \mathrm{m}^{-2} \cdot \mathrm{s}^{-1}$ (bottom) light intensities. Each value is a mean of 3 replicates. Error bars are \pm SE.

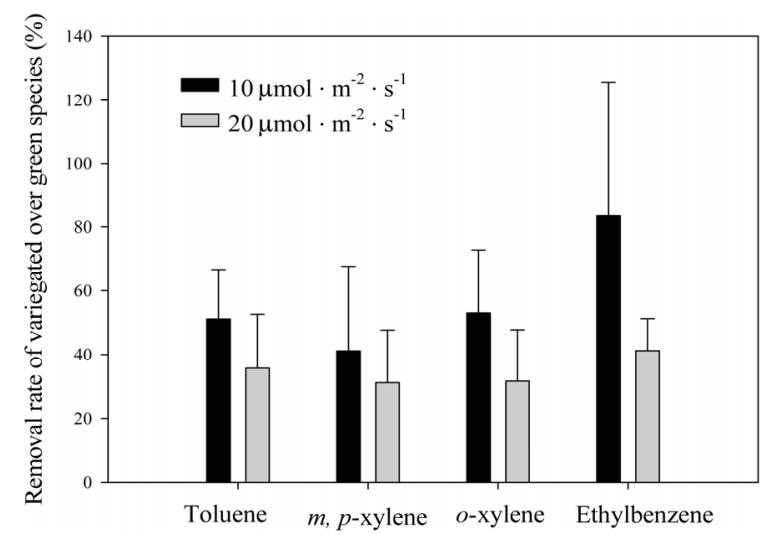

Figure 10. Percentage of VOC removal by variegated plants over green plants of $A$. pusilla, S. aureus, and $H$. helix grown under 10 and $20 \mu \mathrm{mol} \cdot \mathrm{m}^{-2} \cdot \mathrm{s}^{-1}$ light intensities. Values were calculated using the formula: $\%=$ $\left(\frac{\text { VOC r emoval of variegated plants }}{\text { VOC removal of green plants }} \times 100\right)$. Each value is a mean of 3 replicates. Error bars are \pm SE. 
From these results, in general, it can be stated that variegated plant forms have increased VOC removal rates and efficiency under lower light intensity. Variegated plants grown in $10 \mu \mathrm{mol} \cdot \mathrm{m}^{-2} \cdot \mathrm{s}^{-1}$ showed higher VOC removal than green plants by $57.2 \%$ at $15 \mathrm{~h}$ after VOC exposure, while under higher light intensity of $20 \mu \mathrm{mol} \cdot \mathrm{m}^{-2} \cdot \mathrm{s}^{-1}$, the removal rate of variegated plants was $35 \%$ higher than green plants (Fig. 10). This means that variegated plants have about $22 \%$ higher removal rate performance than green plants in $10 \mu \mathrm{mol} \cdot \mathrm{m}^{-2} \cdot \mathrm{s}^{-1}$ than in $20 \mu \mathrm{mol} \cdot \mathrm{m}^{-2} \cdot \mathrm{s}^{-1}$.

Light intensity is a critical factor in plant growth and development. Indoor plants, though requiring less light than outdoor plants, require specific light intensity for proper growth and development. Indoor plants are also known to uptake indoor air pollutants, and environmental factors influence their capacity to absorb the pollutants. Several indoor plant species have forms such as variegation that make them more attractive and therefore more preferred by consumers. This study investigated the VOC removal efficiency of three indoor plant species with green and variegated leaves grown under two light intensities. This is the first report on the effect of variegation and light intensity on the VOC removal efficiency of indoor plants.

Previous reports showed a positive effect of increased light intensity on VOC removal (Oyabu et al., 2005b; Sawada and Oyabu, 2008; Baosheng et al., 2009). These reports, however, did not compare leaf forms, as was done in this study. As shown in this present study, variegated leaves responded differently under different light conditions in terms of their VOC removal. A rise in VOC removal in increasing light intensities can be expected if the VOC is taken up through the stomata (Dela Cruz et al., 2014). The stomata are known to be regulated by light intensity (Roelfsema and Hedrich, 2005), among other factors. Kil et al. (2008) observed that light intensity affects the removal efficiency of formaldehyde in Epipremnum aureum (syn. S. aureus) and Fatsia japonica. Baosheng et al. (2009) working on Phoenix roebelenii found that as light intensity increased, the purifying ability of the plant also increased. However, the increase was only observed in light intensities greater than $300 \mathrm{~lx}\left(\sim 4.2 \mu \mathrm{mol} \cdot \mathrm{m}^{-2} \cdot \mathrm{s}^{-1}\right)$. Kondo et al. (1995) also reported that the absorption rate of Nerium indicum of formaldehyde increased with increasing photosynthetic photon flux density. This result was attributed to the decrease in the total diffusive resistance. Of the plants evaluated in this present study, removal of VOC by $H$. helix apparently was not affected by light intensities from 10 to $20 \mu \mathrm{mol} \cdot \mathrm{m}^{-2} \cdot \mathrm{s}^{-1}$. Yoo et al. (2006) also observed that removal of benzene or toluene by H. helix is not affected by day or night condition, implying that stomatal diffusion in H. helix is not a major factor affecting VOC removal efficiency of the plant. Moreover, Aphalo and Sanchez (1986) observed that the white and green sectors of variegated H. helix have the same number of stomata, while Beerling and Woodward (1995) observed that in other plants, the number of stomata in the green and white sectors of variegated plants differ in stomatal density. Similarly, they have observed similar stomatal density in white and green sectors of variegated $H$. helix. Although growth and thereby photosynthetic activity of variegated $H$. helix is more negatively affected in low light intensity (2 $\mu \mathrm{mol} \cdot \mathrm{m}^{-2} \cdot \mathrm{s}^{-1}$ ) than its green counterpart as observed by Khalekuzzaman et al. (2015), light intensity apparently did not affect the removal rate of variegated and green forms of $H$. helix in our study. While variegated $H$. helix has been more studied previously by several authors, variegated A. pusilla and S. aureus have not been studied as much. It is hypothesized that in lower light intensity such as $10 \mu \mathrm{mol} \cdot \mathrm{m}^{-2} \cdot \mathrm{s}^{-1}$, variegated forms have a better adaptability, causing them to have higher VOC removal efficiency and removal rate. Moreover, it has been suggested that variegated forms of plants have some adaptive advantage that make them persist and prevail in a given environmental condition (Sheue et al., 2012; Pao et al., 2014; Chen et al., 2017). It has also been suggested by Beerling and Woodward (1995) that non-uniform stomatal responses (density and index) to increases in $\mathrm{CO}_{2}$ of green and variegated sectors of different plant species could be due to heterobaric and homobaric leaf structures of the different plants. H. helix is known to have heterobaric leaves, wherein the vascular bundles isolate interveinal areas, restricting the diffusion of $\mathrm{CO}_{2}$ through the mesophyll. Homobaric leaves, on the other hand, allow large gaseous flux by their well-connected intercellular spaces (Mansfield et al., 1990). Physiological 
differences in green and variegated leaves may be attributed for the variance in the removal rate and the efficiency of these indoor plants under different light conditions.

\section{Conclusion}

The efficiency of plants in removing pollutants is affected by many factors. These may be biological or physical factors. In this study, we demonstrated that plant form and light intensity are important factors that affect the VOC removal efficiency of plants. Generally, variegated plant forms achieve increased removal of VOC under lower light intensity, and this tendency is more pronounced in A. pusilla and S. aureus. Green and variegated $H$. helix have less sensitivity to light intensity in terms of VOC removal. Under higher light intensity conditions, the difference in the VOC removal rate of variegated and green plants was not so evident. A thorough understanding of the physiological differences or mechanism of VOC removal by variegated and green plant forms under different environmental conditions could be valuable in maximizing the utilization of foliage plants for indoor air quality improvement.

\section{References}

Aphalo, P.J. and R.A. Sanchez. 1986. Stomatal responses to light and drought stress in variegated leaves of Hedera helix. Plant Physiol. 81(3):768-773. DOI: 10.1104/pp.81.3.768

Aydogan, A. and L.D. Montoya. 2011. Formaldehyde removal by common indoor plant species and various growing media. Atmos. Environ. 45:2675-2682. DOI: 10.1016/j.atmosenv.2011.02.062

Baosheng, K., S. Shibata, and A. Sawada. 2009. Air purification capability of potted Phoenix roebelenii and its installation effect in indoor space. Sens. Mater. 21(8):445-455.

Beerling, D.J. and F.I. Woodward. 1995. Stomatal responses of variegated leaves to $\mathrm{CO}_{2}$ enrichment. Ann. Bot. 75(5): 507-511. DOI: 10.1006/anbo.1995.1052

Brown, S.K. 1997. Volatile organic compounds in indoor air: Source and control. Chem. Aust. 64:10-13.

Campitelli, B.E., I. Stehlik, and J.R. Stinchcombe. 2008. Leaf variegation is associated with reduced herbivore damage in Hydrophyllum virginianum. Botany 86(3):306-313. DOI: 10.1139/B07-139

Chen, J. and R.J. Henny. 2008. Ornamental foliage plants: Improvement through biotechnology. Recent advances in plant biotechnology and its applications. IK International Publishing House Pvt. Ltd., New Delhi, 140-156.

Chen, Y.S., P. Chesson, H.W. Wu, S.H. Pao, J.W. Liu, L.F. Chien, J.W.H. Yong, and C.R. Sheue. 2017. Leaf structure affects a plant's appearance: combined multiple-mechanisms intensify remarkable foliar variegation. J. Plant Res. 130(2): 311-325. DOI: 10.1007/s10265-016-0890-4

Dela Cruz, M., J.H. Christensen, J.D. Thomsen, and R. Müller. 2014. Can ornamental potted plants remove volatile organic compounds from indoor air? - A review. Environ. Sci. Pollut. Res. 21(24):13909-13928. DOI: 10.1007/s11356-014$3240-x$

Feng, Y.L., K.F. Cao, and J.L. Zhang. 2004. Photosynthetic characteristics, dark respiration, and leaf mass per unit area in seedlings of four tropical tree species grown under three irradiances. Photosynthetica 42(3):431-437. DOI: 10.1023/ B:PHOT.0000046163.83729.e5

Fisk, W.J. 2000, August. Review of health and productivity gains from better IEQ. Proc. of Health Buildings 2000, SIY Indoor Air Information, Oy, Helsinki. Abstract retrieved from https://escholarship.org/content/qt57c3z448/qt57c3z4488.pdf

Hines, A.L., T.K. Ghosh, S.K. Loylka, and R.C. Warder. 1993. Indoor air: Quality and control., Englewood Cliffs, N.J. USA: Prentice Hall.

Irga, P.J., F.R. Torpy, and M.D. Burchett. 2013. Can hydroculture be used to enhance the performance of indoor plants for the 
removal of air pollutants? Atmos. Environ. 77:267-271. DOI: 10.1016/j.atmosenv.2013.04.078

Khalekuzzaman, M., K.J. Kim, H.J. Kim, H.H. Jung, and H.S. Jang. 2015. Comparison of green and variegated foliage plant species based on chlorophyll fluorescence parameters under different light intensities. Pak. J. Bot. 47:1709-1715.

Kil, M.J., K.J. Kim, J.K. Cho, and C.H. Park. 2008. Formaldehyde gas removal effects and physiological responses of Fatsia japonica and Epipremnum aureum according to various light intensity. Korean J. Hortic. Sci. Technol. 26(2):189-896.

Kim, K.J., E.H. Yoo, and S.J. Kays. 2012. Decay kinetics of toluene phytoremediation stimulation. HortScience 47(8): 1195-1198.

Kim, K.J., E.H. Yoo, M.I. Jeong, J.S. Song, S.Y. Lee, and S.J. Kays. 2011. Changes in the phytoremediation potential of indoor plants with exposure to toluene. HortScience 46(12):1646-1649.

Kim, K.J., H.H. Jung, H.W. Seo, J.A. Lee, and S.J. Kays. 2014. Volatile toluene and xylene removal efficiency of foliage plants as affected by top to root zone size. HortScience 49(2):230-234.

Kim, K.J., M.I. Jeong, D.W. Lee, J.S. Song, H.D. Kim, E.H. Yoo, S.J. Jeong, S.W. Han, S.J. Kays, Y.W. Lim, and H.H. Kim. 2010. Variation in formaldehyde removal efficiency among indoor plant species. HortScience 45(10):1489-1495.

Kim, K.J., M.J. Kil, J.S. Song, E.H. Yoo, K.C. Son, and S.J. Kays. 2008. Efficiency of volatile formaldehyde removal by indoor plants: Contribution of aerial plant parts versus the root zone. J. Am. Soc. Hortic. Sci. 133(4):521-526.

Kondo, T., K. Hasegawa, R. Uchida, M. Onishi, A. Mizukami, and K. Omasa. 1995. Absorption of formaldehyde by oleander (Nerium indicum). Environ. Sci. Technol. 29(11):2901-2903.

Liu, X. 2007. Identification of appropriate CFD models for simulating aerosol particle and droplet indoor transport. Indoor Built Environ. 16(4):322-330. DOI: 10.1177/1420326X06079890

Maloof, J.N., J.O. Borevitz, T. Dabi, J. Lutes, R.B. Nehring, J.L. Redfern, J.T. Trainer, J.M. Wilson, T. Asami, C.C. Berry, D. Weigel, and J. Chory. 2001. Natural variation in light sensitivity of Arabidopsis. Nat. Genet. 29:441-446. DOI: $10.1038 / \mathrm{ng} 777$

Manaker, G.H. 1997. Interior plantscapes: Installation, maintenance, and management. $3^{\text {rd }}$ ed. Upper Saddle River, N.J., USA: Prentice Hall.

Mansfield, T.A., A.M. Hetherington, and C.J. Atkinson. 1990. Some current aspects of stomatal physiology. Annu. Rev. Plant Physiol. Plant Mol. Biol. 41:55-75. DOI: 10.1146/annurev.pp.41.060190.000415

Marcotrigiano, M. 1997. Chimeras and variegation: Patterns of deceit. HortScience 32(5):773-784.

Orwell, R.L., R.L. Wood, J. Tarran, F. Torpy, and M.D. Burchett. 2004. Removal of benzene by the indoor plant/substrate microcosm and implications for air quality. Water Air Soil Pollut. 157(1-4):193-207. DOI: 10.1023/B:WATE. $0000038896.55713 .5 \mathrm{~b}$

Orwell, R.L., R.L. Wood, M.D. Burchett, J. Tarran, and F. Torpy. 2006. The potted-plant microcosm substantially reduces indoor air VOC pollutant: II. Laboratory study. Water Air Soil Pollut. 177(1-4):59-80. DOI: 10.1007/s11270-006-9092-3

Oyabu, T., A. Sawada, H. Kuroda, T. Hashimoto, and T. Yoshioka. 2005a. Purification capabilities of golden pothos and peace lily for indoor air pollutants and its application to a relaxation space. J. Agric. Meterol. 60(6):1145-1148. DOI: 10.2480/agrmet.1145

Oyabu, T., T. Onodera, A. Sawada, and M. Tani. 2005b. Purification characteristics of golden pothos for emitting airpollutants from plywood using a gas sensor. WIT Trans. Biomed. Health. 9: 9. DOI: 10.2495/EHR050241

Pao, S.H., P. Chesson, C.I. Peng, W.B. Yeh, and C.R. Sheue. 2014. Characteristics and ecological significance of natural variegation from Begonia formosana. In The 99th Annual Meeting, 10th-15th August, Ecological Society of America. Sacramento, California, USA.

Roelfsema, M. and R. Hedrich. 2005. In the light of stomatal opening: new insights into "The Watergate." New Phytol. 167(3):665-691. DOI: 10.1111/j.1469-8137.2005.01460.x

Runeson, R., K. Wahlstedt, G. Wieslander, and D. Norback. 2006. Personal and psychological factors and symptoms compatible with sick building syndrome in the Swedish workforce. Indoor Air 16(6):445-453. DOI: 10.1111/ 


\section{j.1600-0668.2006.00438.x}

Sawada, A. and T. Oyabu. 2008. Purification characteristics of pothos for airborne chemicals in growing conditions and its evaluation. Atmos. Environ. 42(3):594-602. DOI: 10.1016/j.atmosenv.2007.10.028

Sheue, C.R., S.H. Pao, L.F. Chien, P. Chesson, and C.I. Peng. 2012. Natural foliar variegation without costs? The case of Begonia. Ann. Bot. 109(6):1065-1074. DOI: 10.1093/aob/mcs025

Sims, D.A. and R.W. Pearcy. 1992. Response of leaf anatomy and photosynthetic capacity in Alocasia macrorrhiza (Araceae) to a transfer from low to high light. Am. J. Bot. 79(4):445-449.

Tsai, D.H., J.S Lin, and C.C. Chan. 2012. Office worker's sick building syndrome and indoor carbon dioxide concentrations. J. Occup. Environ. Hyg. 9(5):345-351. DOI:10.1080/15459624.2012.675291

Torpy, F.R., P.J. Irga, D. Moldovan, J. Tarran, and M.D. Burchett. 2013. Characterization and biostimulation of benzene biodegradation in the potting-mix of indoor plants. J. Appl. Hortic. 15(1):10-15.

Wang, B.L., T. Takigawa, A. Takeuchi, Y. Yamasaki, H. Kataoka, D.H. Wang, and K. Ogino. 2007. Un-metabolized VOCs in urine as biomarkers of low level exposure in indoor environments. J. Occup. Health 49(2):104-110. DOI: /10.1539/joh.49.104

Wolkoff, P. 2003. Trends in Europe to reduce the indoor air pollution of VOCs. Indoor Air 13(6):5-11. DOI: 10.1034/ j.1600-0668.13.s.6.1.x

Wolverton, B.C. and J.D. Wolverton. 1993. Plants and soil micro-organisms-removal of formaldehyde, xylene and ammonia from the indoor environment. J. Miss. Acad. Sci. 38(2):11-15.

Yoo, M.H., Y.J. Kwon, K.C. Son, and S.J. Kays. 2006. Efficacy of indoor plants for the removal of single and mixed volatile organic pollutants and physiological effects of the volatiles on the plants. J. Am. Soc. Hortic. Sci. 131(4):452-458. 